\section{Factores comunes e inductores de inflamación en asma y obesidad}

\author{
Gloria Bertha Vega-Robledo ${ }^{1}$, Rodrigo Huerta-Gutiérrez de Velasco ${ }^{2}$, Gua-
} dalupe Rico-Rosillo ${ }^{1}$

\section{Resumen}

La incidencia de asma y obesidad está en aumento, por lo que se han catalogado como problemas de salud pública. Los datos epidemiológicos sugieren una relación entre ellas y se ha detectado una asociación entre el índice de masa corporal y la función pulmonar. Diversos estudios demuestran una correlación directa entre este índice y el asma. Mediante la búsqueda de referencias en bases de datos médicos de artículos publicados en revistas indizadas, con las palabras clave asma y obesidad: patogénesis, inflamación, adipocinas, hipoxia, nutrición, embarazo, este artículo profundiza en el conocimiento de los elementos básicos que interrelacionan el asma con la obesidad. Se encontró que la asociación existente entre el índice de masa corporal y el asma es más evidente en el sexo femenino. El asma y la obesidad pueden estar influidas por elementos genéticos y programación fetal. A su vez, la obesidad puede incidir en el asma por diversos mecanismos, como los mecánicos, hormonales o inflamatorios. La coincidencia existente entre varios inductores y elementos que exacerban a estas enfermedades, así como en algunas vías moleculares, ponen de manifiesto una relación potencial entre ambas afecciones.

PALABRAS CLAVE: asma, obesidad, inflamación, adipocinas, hipoxia.

Rev Alerg Méx 2016 Jan-Mar;63(1):41-57.

\section{Common and inductors factors of inflammation in asthma and obesity.}

Gloria Bertha Vega-Robledo ${ }^{1}$, Rodrigo Huerta-Gutiérrez de Velasco², Guadalupe Rico-Rosillo ${ }^{1}$

\begin{abstract}
The incidence of asthma and obesity is increasing, therefore they have been classified as public health problems; epidemiology suggests a link between these diseases. It has been detected a relationship between the body mass index and lung function, moreover some works show a direct correlation between the aforementioned index and severity of asthma. By a search for articles in indexed journals from medical databases with the key words asthma and obesity: pathogenesis, inflammation, adipokines, hypoxia, nutrition, pregnancy, this paper deeps in the knowledge about basic elements that offer an asthma and obesity link. It was found that the association between body mass index and asthma is more frequent in women. Asthma and obesity might be influenced by genetic elements and fetal programming; at the same time obesity could influence asthma by several mechanisms such as inflammation, hormones and mechanical respiratory dysfunction. The existing coincidence between several inducers and factors which exacerbate these diseases as well as in some molecular routes shows a potential relation between both pathological entities.
\end{abstract}

KEYWORDS: asthma; obesity; inflammation; adipokines; hipoxia
${ }^{1}$ Unidad de Medicina Experimental, Facultad de Medicina.

${ }^{2}$ Facultad de Medicina.

Universidad Nacional Autónoma de México, Ciudad de México.

Recibido: 27 de noviembre 2015

Aceptado: 8 de enero 2016

Correspondencia

Dra. Gloria Bertha Vega Robledo

gloriavr@liceaga.facmed.unam.mx

Este artículo debe citarse como

Vega-Robledo GB, Huerta-Gutiérrez de Velasco R, Rico-Rosillo G. Factores comunes e inductores de inflamación en asma y obesidad. Rev Alerg Méx. 2016 ene-mar;63(1):41-57. 


\section{ANTECEDENTES}

La incidencia de asma y de obesidad aumentaron mundialmente en fechas recientes, convirtiéndose en problemas de salud pública. ${ }^{1}$ Ante la evidencia epidemiológica que sugiere una relación entre ambos padecimientos ${ }^{2}$ se hace necesaria la investigación básica con el fin de encontrar vínculos fisiopatológicos.

Además de una posible relación causal directa, se han señalado otras asociaciones, como la eficacia del tratamiento contra el asma, su severidad y la obesidad. Aun cuando la relación con la inflamación no se ha identificado totalmente, ${ }^{3}$ se ha visto que el control de la obesidad influye en el alivio de los síntomas asmáticos. ${ }^{4}$ Acorde con lo anterior, para su tratamiento y control resulta esencial el conocimiento de los fundamentos básicos que puedan ligar a esta enfermedad con la obesidad. Esta revisión tiene como objetivo mostrar diferentes hipótesis que pretenden explicar una posible relación fisiopatogénica entre el asma y la obesidad.

\section{Obesidad}

La obesidad es el depósito excesivo de grasa en el organismo, como consecuencia del desequilibrio entre los ingresos energéticos y la actividad física. Se relaciona con el índice de masa corporal (IMC), que es el criterio más utilizado para definirla. AI respecto, se considera que un IMC igual o mayor a 30 corresponde a obesidad y de 25 a 29.9 corresponde a sobrepeso.

Los estudios efectuados en 17 países, entre ellos México, reportan una prevalencia de obesidad de 4.5 a $32 \%$. Estados Unidos, con $32 \%$ de adultos obesos y con sobrepeso, ocupa el primer lugar en el mundo, México el segundo lugar y el primero en mujeres con obesidad. En México, $71 \%$ de los adultos mayores de 20 años tiene obesidad o sobrepeso, de acuerdo con los datos obtenidos en la Encuesta Nacional de Salud y Nutrición 2012. ${ }^{5}$
Este aumento se asocia con cambios socioeconómicos, tecnológicos y familiares, favorecedores del sedentarismo y conducentes al equilibrio energético positivo.

\section{Asma}

Es una enfermedad compleja que se distingue por hiperreactividad bronquial, inflamación de las vías aéreas y síntomas como sibilancias, tos y disnea, relacionados con la obstrucción intermitente del flujo aéreo. Estas alteraciones inflamatorias, al tornarse crónicas, pueden causar remodelación de las estructuras broncopulmonares.

La prevalencia del asma en el mundo varía ampliamente: de menos de $5 \%$ de la población en Grecia a más de $25 \%$ en Australia y Nueva Zelanda. En México se registra una prevalencia entre 5 y $7 \%$ y constituye una de las 10 primeras causas de utilización de los servicios de salud por los adultos. ${ }^{6}$

En niños y adultos el asma está estrechamente relacionada con el índice de masa corporal y algunos estudios indican que esta relación se observa con mayor frecuencia en mujeres que en hombres. Señalan también que el índice de masa corporal se correlaciona directamente con la función pulmonar y la disminución de peso, con su mejoría.?

Cuando la obesidad y el asma coexisten provocan daños individuales, económicos y sociales severos. Ambas enfermedades parecen estar ligadas por diversos mecanismos que incluyen, entre otros: exposiciones comunes, factores genéticos, hormonales, inflamación y comorbilidad. ${ }^{8}$

\section{Genética}

Varios alelos se han asociado con el asma y la obesidad, por lo que la interacción de estos genes, de acuerdo con la función de las proteínas que codifican, ofrece diferentes explicaciones 
causales comunes para estas dos enfermedades. El polimorfismo TNF- $\alpha$-308 del gen que codifica para el factor de necrosis tumoral alfa (TNF- $\alpha$ ) está implicado en ambas enfermedades, así como el Gln27->Glu del receptor $\beta 2$-adrenérgico. El polimorfismo -2549T/G (rs2167270) del gen que codifica a la leptina se asocia con el asma y con un índice de masa corporal elevado. ${ }^{9}$ Además, se han descrito algunos alelos del receptor de la vitamina D y su relación con el asma ${ }^{10}$ y con la obesidad. ${ }^{11}$

Algunos genes vinculados con la inflamación e implicados en el equilibrio energético se heredan juntos por su cercanía cromosómica, como los de las proteínas desacoplantes 1 y 2 (UCP1, UCP2) y el del receptor beta de la inmunoglobulina E; ambos localizados en la posición 11q13. Otras regiones cromosómicas en las que hay genes para asma y trastornos metabólicos relacionados con obesidad son las porciones $12 q, 5 q$ y $6 p$. Al respecto, se han efectuado estudios de asociación del genoma completo; uno realizado por Melen, ${ }^{12}$ que no mostró asociaciones entre asma y obesidad, y otro señalado por Tesse, en el que revisó y comparó diversos análisis genéticos y encontró señales traslapadas de locus en 3q,4q, 5q, 6p, 7q, 11p, 16q, $17 q, 18 q$ y $22 q^{13}$ para asma, diabetes y obesidad.

\section{Exposiciones comunes}

Desde que se planteó la hipótesis de la higiene, las exposiciones en la vida temprana a modificadores de la respuesta inmunitaria, como la alimentación, y las infecciones se han considerado importantes en la patogenia del asma. El asma y la obesidad pueden iniciar en la infancia, las exposiciones comunes que predisponen a los individuos a estas dos condiciones explican algunos vínculos entre ellas. Las dos enfermedades están sujetas a elementos comunes, como la alimentación, la nutrición materna, el peso al nacer, el aumento de peso durante la infancia, los patrones de la microbiota intestinal, el ejercicio y las concentraciones altas de adipocinas. ${ }^{14}$

\section{Embarazo y prematurez}

En estudios recientes se ha visto que el aumento de peso durante el embarazo predispone a los hijos a padecer asma. ${ }^{15}$ En mujeres con y sin embarazo, el incremento en el índice de masa corporal se relaciona con el aumento en las concentraciones de leptina; los receptores para leptina están presentes en el pulmón fetal y pueden contribuir al desarrollo de este órgano en el útero.

La privación de alimento in utero y el bajo peso al nacer, así como la prematurez, son factores considerados predisponentes para padecer obesidad en la adultez. Una madre mal nutrida, que no acumula las grasas necesarias en cantidad y en calidad, tiene más probabilidades de dar a luz un niño con bajo peso. La dieta durante el primer trimestre del embarazo es fundamental porque este periodo se llama de "programación fetal", lo que se refiere a las alteraciones genéticas producidas por la mala nutrición materna y por todas las agresiones que sufre el feto o el recién nacido y que se manifestarán en el desarrollo posnatal y durante toda la vida del producto. ${ }^{16}$

Al respecto, en estudios realizados en los descendientes de personas que sufrieron hambre en Holanda durante la segunda Guerra Mundial, se observó que los niños que nacieron con bajo peso mostraron en la vida adulta una significativa incidencia de obesidad y síndrome metabólico, en comparación con los descendientes de la población que no sufrió hambre. ${ }^{16}$

\section{Vitaminas y antioxidantes}

\section{Vitamina $D$}

Está implicada en el asma grave resistente al tratamiento y en la obesidad. Algunos estudios señalan que las concentraciones séricas de esta vitamina se relacionan inversamente con la severidad del asma y directamente con el 
control de la enfermedad. La vitamina D participa en el sistema inmunitario innato y en el adaptativo. En el primero, además del efecto modulador de la vitamina en la inflamación de las mucosas, su disminución se asocia con incremento en la expresión del TNF- $\alpha$, citocina proinflamatoria participante en el asma y la obesidad. En el sistema adaptativo, induce la diferenciación y modula la función de células T reguladoras productoras de TGF- $\beta$ e IL-10, ${ }^{17}$ citocinas antiinflamatorias que mejoran la respuesta a glucocorticoides en individuos resistentes. ${ }^{18}$

En niños obesos se han detectado concentraciones séricas de vitamina $\mathrm{D}$ más bajas que en los de peso normal y sus concentraciones se correlacionaron negativamente con el índice de masa corporal. ${ }^{19}$

\section{Antioxidantes}

El potencial de los antioxidantes provenientes de la dieta, como las vitaminas $\mathrm{C}, \mathrm{A}$ y $\mathrm{E}$, en la aparición del asma continúa en estudio porque los resultados hasta el momento son contradictorios. ${ }^{20}$ Las concentraciones de los antioxidantes mencionados se han encontrado disminuidas en la sangre de pacientes obesos. Varios estudios establecen una asociación entre la obesidad y la escasa ingestión de antioxidantes, sus concentraciones plasmáticas bajas y algunos cambios en la actividad de las enzimas antioxidantes. ${ }^{21}$

Alan y colaboradores señalaron que la vitamina E protege contra la lipoperoxidación y ejerce una función de depuración al inactivar a varias especies reactivas de oxígeno, como $\mathrm{HO}, \mathrm{O}_{2}^{-}$y $\mathrm{O}_{2}$, que aumentan en la obesidad y el asma. Algunos estudios demuestran que la deficiencia de vitamina E durante el embarazo aumenta el riesgo del producto de padecer enfermedades alérgicas, principalmente asma. ${ }^{22}$

\section{Microbiota}

La población microbiana participa en la madurez de la barrera mucosa y de tejidos inmunitarios, así como en la tolerancia a los alimentos. La dieta se ha asociado con enterotipos humanos: Bacteroides cuando es alta en proteínas y grasas saturadas y Prevotella con dieta baja en proteína y grasas, pero elevada en carbohidratos y azúcar simple. ${ }^{23}$

La presencia, composición y acciones metabólicas de la flora intestinal pueden influir de manera importante en el metabolismo energético en ratones y humanos. La microbiota aumenta el almacén de energía del hospedero a través de la hidrólisis y fermentación de polisacáridos de la dieta que él no puede digerir. La fermentación microbiana genera monosacáridos y ácidos grasos de cadena corta que pueden ser absorbidos y utilizados como energía por el hospedero. ${ }^{24}$

La microbiota y algunos receptores celulares para patrones moleculares asociados con patógenos (PAMP'S), como los TLR (del inglés: toll-like receptors)-2, son necesarios para el desarrollo de células $T$ reguladoras. Cuando la microbiota comensal pasa a la lámina propia de manera transitoria y en baja cantidad, estimula la formación de células T reguladoras y con ello protege al intestino de la inflamación. Por el contrario, cuando el epitelio intestinal está dañado y permite el paso de una gran cantidad, la microbiota genera mayor inflamación. ${ }^{25}$

En animales obesos, la permeabilidad del intestino y las concentraciones séricas de lipopolisacáridos son mayores, lo que podría originar o ser una fuente constante de señales inflamatorias.

Los estudios en animales a los que se les indujo un incremento intestinal de bifidobacterias mostraron una correlación positiva con mejoría en la tolerancia a la glucosa y normalización de los bajos niveles de inflamación. ${ }^{26}$ 
Estudios epidemiológicos en niños y adolescentes señalan fluctuaciones en la flora del tubo gastrointestinal cuando se asocia con obesidad y su reestructuración al bajar de peso. En niños preescolares con sobrepeso encontraron aumento significativo de Enterobacteriaceae y disminución de Desulfovibrio. ${ }^{27}$

En adultos sanos predominan los enterotipos Bacteroides, Prevotella y Firmicutes. Se ha tratado de asociar diversos patrones de colonización bacteriana del intestino con la obesidad; así, varios autores encontraron un número reducido de Bacteroides y más consistentemente un incremento de Firmicutes. ${ }^{28}$ Los pacientes con asma también tienen menor cantidad de Bacteroides, pero mayor proporción de Clostridium difficile.

Lo señalado ha generado un marcado interés en el estudio de las posibles aplicaciones terapéuticas de los probióticos en estas dos enfermedades. ${ }^{29}$

\section{Hormonas e interacción endocrinológica}

\section{Estrógenos y progesterona}

Estudios epidemiológicos apuntan a una relación más fuerte entre asma y obesidad según el género y la mayor parte señala el predominio en mujeres; incluso Chen y colaboradores denotan la ausencia de esta relación en los hombres. ${ }^{30} \mathrm{Al}$ respecto, un estudio realizado en el servicio de Alergia del Hospital General de México mostró que $71 \%$ de los pacientes asmáticos tuvieron peso superior al normal, de los que $33 \%$ pertenecía al sexo masculino y $77 \%$ al femenino. ${ }^{31}$

Lo anterior podría estar relacionado con efectos del estrógeno y la progesterona en el sistema inmunitario, como el establecimiento de una respuesta Th2 y la inhibición de la apoptosis de estos linfocitos. Algunos autores señalan que los estrógenos aumentan la producción de las citocinas IL-4 e IL-13 en células mononucleares periféricas. ${ }^{32}$ Estas citocinas son inductoras de la respuesta Th2, por lo que la mayor liberación puede incrementar la actividad alérgica.

En mujeres posmenopáusicas los estrógenos exógenos administrados como terapia de reemplazo hormonal se asocian con incremento del riesgo de padecer asma. ${ }^{33}$

Los estrógenos, que están aumentados en la obesidad, pueden modular la respuesta de las células inflamatorias de las vías aéreas. Por el contrario, la progesterona, que favorece la relajación de las vías aéreas, está disminuida en este padecimiento.

Algunos autores señalan que la masa magra total se asocia más estrechamente con el asma que la masa de grasa total, lo que sugiere que la grasa ectópica dentro de los tejidos magros puede participar de manera importante en la asociación obesidad-asma en mujeres. ${ }^{34}$

El tejido adiposo es un importante sitio extragonadal productor de estrógenos, sobre todo en obesos. En la obesidad, los estrógenos pueden generarse también a partir de andrógenos y de esteroides en el tejido adiposo. La androstenediona y otros andrógenos adrenales son convertidos a estrona (E1) por la aromatasa en el tejido adiposo; a partir de la estrona se forma el estrógeno biológicamente más activo, el 17 $\beta$-estradiol (E2), que regula la lipólisis y estimula la proliferación de preadipocitos en el tejido adiposo y que, en la circulación, se puede transformar en partículas de lipoproteínas de alta densidad. En hombres obesos también aumentan E1 y E2. ${ }^{35}$

En ratones, los estrógenos y sus receptores en los adipocitos regulan la distribución, expansión, inflamación y fibrosis del tejido adiposo, así como la homeostasia de la glucosa. ${ }^{36}$ En mujeres con ooforectomía aumenta el peso y el depósito de tejido adiposo intraabdominal, lo que disminuye 
con la terapia de reemplazo con estrógenos y mejora la homeostasia de la glucosa. ${ }^{37}$ La disminución del peso podría contrarrestar el riesgo de las pacientes de padecer asma por el efecto de esta hormona.

\section{Corticoesteroides}

En pacientes asmáticos tratados con corticoesterides, la producción hormonal puede encontrarse aún más alterada debido a que en el tejido adiposo estimulan la formación de estrógenos, la transformación de células precursoras en adipocitos e inhiben la expresión génica de la adiponectina, adipocina antiinflamatoria que está disminuida en asmáticos con obesidad. ${ }^{38}$

\section{Respuesta al tratamiento con corticoesteroides}

Los glucocorticoides son inmunomoduladores prescritos en el tratamiento del asma y en los pacientes asmáticos obesos la respuesta a estos fármacos disminuye o está ausente. ${ }^{39} \mathrm{Sin}$ embargo, la acción de los glucocorticoides es muy amplia y la comparación con otros agentes inmunomoduladores resulta útil. Se ha observado la falta de respuesta a los glucocorticoides, pero no a bloqueadores de receptores de los leucotrienos, y mientras que la eficacia de la beclometasona se relaciona inversamente con el índice de masa corporal, la de antileucotrienos aumenta de manera paralela, no obstante el aumento en la concentración de leucotrienos B4 (LB4) encontrado en pacientes con obesidad y asma. ${ }^{40}$ Aun cuando los leucotrienos estén aumentados en individuos asmáticos obesos, su unión con los antileucotrienos es factible y, por tanto, la inflamación originada por esta vía puede bloquearse. En tanto que los blancos, los receptores (o ambos) utilizados por los corticoesteroides pueden estar alterados, lo que impediría su acción en ellos y, por ende, su función antiinflamatoria, como sería el caso de receptores o de enzimas, como la desacetilasa de histona.
Con el fin de encontrar la causa de la disminución de la eficacia del tratamiento en relación con el aumento en el índice de masa corporal, se ha propuesto una posible relación entre la producción aumentada de TNF- $\alpha$ e IL-6 por los macrófagos activados de manera clásica (inflamatoria) durante la obesidad y la pérdida de sensibilidad de los receptores de glucocorticoides. ${ }^{41}$ Debido al efecto de los corticoesteroides en la desacetilación de histonas, también se ha propuesto una pérdida de la expresión y actividad de la histona desacetilasa como mecanismo de resistencia a los corticoesteroides, causada por el daño oxidativo propio del asma. ${ }^{42}$ Los aniones superóxido y el peroxinitrito bloquean la actividad enzimática de la HDAC 2 y la marcan para ubiquitinación y destrucción por el proteasoma.

Las deacetilasas (HDAC) de histonas normalmente reprimen la expresión de genes inflamatorios, de manera que al haber pérdida de la función de esta enzima, el efecto que el corticoesteroide ejercería en ella no se logra y la inflamación no cede.

Algunos estudios señalan que la eferocitosis o eliminación de células apoptóticas por macrófagos de las vías aéreas o monocitos sanguíneos está alterada en los pacientes asmáticos obesos y se correlaciona inversamente con la respuesta a glucocorticoides. ${ }^{43}$

\section{Inflamación}

Una de las principales causas de la inflamación en el asma es la reacción alérgica, ocasionada por el contacto con elementos desencadenantes. En ella, hay una hiperrespuesta de las vías respiratorias y la inflamación se distingue por infiltrado de eosinófilos y linfocitos Th2. La inflamación en el asma puede ser inducida también por mecanismos no alérgicos.

En ambos casos, la liberación de mediadores inflamatorios y citocinas tiene como origen a 
células, como las epiteliales, los macrófagos y particularmente las cebadas, que son activadas por inductores: IgE principalmente en alergia o lipopolisacáridos, factores del complemento (C3a, C5a), restos de tejidos, etcétera, como desencadenantes de inflamación no alérgica, a los que se suma la eferocitosis fallida.

Aunque el asma es un trastorno inflamatorio de las vías aéreas que involucra a células de la respuesta inmunitaria, hay evidencias del papel tan importante que tiene el epitelio en orquestar la respuesta inflamatoria, por su interacción con múltiples factores ambientales, como alergenos, gérmenes y contaminantes. ${ }^{44}$ Así, se ha observado que las proteasas derivadas de los alergenos inducen ruptura en las uniones de las células epiteliales de las vías aéreas y activan a los receptores ubicados en la superficie de estas células. Al pasar por las capas epiteliales pueden aumentar su alergenicidad, activar al sistema inmunitario o ejercer ambas acciones.

Algunas evidencias indican que el epitelio, como barrera física y funcional de las vías aéreas, es deficiente en asmáticos; se encuentra con uniones dañadas, actividad antioxidante disminuida e inmunidad innata alterada. Esta deficiencia epitelial permite con mayor facilidad el paso de sustancias inhaladas a las vías respiratorias, donde interaccionan con células inflamatorias e inmunitarias, lo que explica la gran susceptibilidad de las vías aéreas de asmáticos a estímulos infecciosos o por contaminantes y su relación con la exacerbación de la enfermedad.

En la obesidad, la inflamación es de baja intensidad, pero crónica. El tejido adiposo, principalmente la grasa visceral, se ha señalado como fuente de citocinas, quimiocinas, adipo$\operatorname{cinas}^{45}$ y otras proteínas, como la $\mathrm{C}$ reactiva, lo que aunado al hallazgo de la infiltración de macrófagos y otras células en ese tejido durante la obesidad, señala a esta condición como favo- recedora de la inflamación. Las concentraciones sistémicas elevadas de marcadores inflamatorios, como IL-1, IL-6, TNF y proteína C reactiva en estos pacientes apoyan esta aseveración. ${ }^{46}$

Aun cuando el tejido adiposo es, en este caso, el órgano central de la inflamación, las secuelas afectan al resto del organismo e inciden importantemente en el páncreas, el músculo, el sistema nervioso, el intestino y el hígado.

A través de la vena porta llegan a este órgano ácidos grasos y adipocinas procedentes del tejido adiposo visceral. Cuando hay un exceso, se altera la producción de citocinas inflamatorias, lo que participa en la génesis de la esteatosis. La inflamación hepática repercute de manera importante en el metabolismo y la patogénesis de otros órganos.

Si bien hay una fuerte evidencia epidemiológica de la asociación entre asma y obesidad, el mecanismo que une a estas dos condiciones permanece poco definido. A continuación se señalan algunos factores como posibles causas de inflamación en ambos padecimientos.

\section{Inflamación por nutrientes}

Se hipotetiza que durante el ciclo ayuno-alimento hay una respuesta inflamatoria mínima, inducida por los nutrientes en los tejidos implicados en su metabolismo, como el adiposo, hepático, pancreático, muscular; la respuesta finaliza cuando se metabolizan. En la obesidad por sobrealimentación hay un estímulo constante en estos sitios por captación de alimentos, lo que activa una respuesta inflamatoria; esta actividad de bajo nivel se acumula y amplifica con las exposiciones frecuentes a nutrientes, lo que empieza a alterar caminos metabólicos (JNK, del inglés: c-jun $N$-terminal kinase; PKR, del inglés: protein kinase $R ; \mathrm{NFkB}$, del inglés: nuclear factor kappa $B$, entre otros), que pueden alertar a las 
células inmunitarias para que participen en la inflamación.

JNK antagoniza señales del receptor para insulina y disminuye a PPAR-g (del inglés: peroxisome proliferator-activated receptor), que disminuye la producción de adiponectina y es un inductor y regulador clave en el proceso de diferenciación adipogénica.

La proteína STAMP-2 (del inglés: six transmembrane protein of prostate 2) aumenta en el tejido adiposo durante la alimentación y tiene propiedades antiinflamatorias en respuesta a la estimulación por nutrientes; si se altera STAMP-2 hay inflamación al contacto del adipocito con alimentos. ${ }^{47}$

Otra hipótesis indica que los alimentos normalmente no son inflamatorios, pero que en exceso pueden activar vías confinadas a patógenos y que los sensores o receptores (PRR, del inglés: pattern recognition receptor) para PAMP's pueden sensar nutrientes, principalmente carbohidratos y grasas.

\section{Ácidos grasos}

En los adipocitos también están presentes los PRR's tipo Toll (TLR) 2 y 4 y los "basurero" (scavenger), que pueden ser activados por ácidos grasos saturados (la ausencia de PRR's protege a modelos animales contra la obesidad). ${ }^{48} \mathrm{Sin}$ embargo, la expresión de TLR-4 no se encontró distinta en pacientes con asma y obesidad. Las vías de señalización utilizadas por los TLR activan al NFkB que sobrerregula la expresión de citocinas inflamatorias (IL-1, IL-6, TNF), así como la respuesta a la glucosa ${ }^{49}$ al inducir resistencia a la insulina. Células como las cebadas y las epiteliales expresan TLR 2, 3 y 4, que median su activación. Algunos autores mencionan que la sobreexpresión de TLR-4 y 2 en células endoteliales de ratones aumenta la aterosclerosis.
Otros PRR's participantes son los NLR (del inglés: nod like receptor) a través del inflamasoma. Este sensor intracelular inicia inflamación activa a la caspasa 1 para que se produzcan citocinas proinflamatorias (IL-1, 18, 33). Está conformado por varias proteínas de la familia NLR, principalmente NLRP3. Esta proteína y el factor inductor de su expresión NFKB pueden ser estimulados por distintos elementos y vías además del TLR, entre los que se encuentran: especies reactivas de oxígeno, desestabilización del lisosoma, cristales de colesterol, hiperglucemia, ácido úrico y lipopolisacáridos. ${ }^{50}$

Se ha encontrado que la reducción de la expresión del inflamasoma NLRP3 en adipocitos, inducida por una dieta restringida en calorías y el ejercicio disminuye la inflamación. Este sensor de daño también es necesario para el desarrollo de una respuesta Th2 en el modelo múrido de asma inducido por ovalbúmina. ${ }^{51}$ Además de lo referido, en relación con la activación de los PRR, la toxicidad de los ácidos grasos se manifiesta también como daño celular.

\section{Daño celular}

Cuando se incrementa el ingreso de ácidos grasos al tejido adiposo hay hiperplasia e hipertrofia de los adipocitos. El crecimiento excesivo puede Ilegar a producir necrosis de la célula. Los restos provenientes de células que mueren por necrosis son quimioatrayentes, lo que aumenta la llegada de células al sitio del daño y la polarización del macrófago al fenotipo inflamatorio. Además de causar necrosis y apoptosis, la sobredistensión celular aumenta el volumen tisular sin generación simultánea de vasos sanguíneos, lo que limita su perfusión y ocasiona hipoxia local. Esto, aunado a la toxicidad inducida por los ácidos grasos, exacerba lo señalado y origina en el resto del tejido disfunción de los constituyentes celulares, entre otros, del retículo endoplasmático y la mitocondria. ${ }^{52}$ 
Hipoxia

El estado de la tensión parcial de oxígeno baja produce la inhibición de la degradación proteosómica del factor inducible por hipoxia $1 \alpha(\mathrm{HIF} 1 \alpha)$ que se heterodimeriza con el HIF $\beta$. Este heterodímero se une a promotores de genes y ocasiona la trascripción de moléculas proinflamatorias, entre las que se encuentran la leptina, la proteína quimioatrayente de monocitos 1 (MCP-1), el factor inhibidor de la migración del macrófago (MIF) y la proteína semejante a angiopoyetina $4,,^{53}$ así como moléculas implicadas en la angiogénesis, la glucólisis, la remodelación de la matriz extracelular, la diferenciación celular y la apoptosis.

También se ha señalado que la hipoxia inhibe a la adiponectina, molécula antiinflamatoria, lo que repercutiría en este proceso. La expresión de IL-6 es sensible a la hipoxia, pero no depende de HIF-1, mientras que el efecto de la hipoxia en la expresión de TNF- $\alpha$ aún es contradictorio. ${ }^{54}$ La hipoxia del tejido adiposo podría agravarse por la baja concentración de oxígeno que se observa en los obesos asmáticos. Además, la hipoxia local del epitelio alveolar aumentaría la polarización celular de los linfocitos hacia Th2, ${ }^{55}$ favorecedores de alergia.

\section{Estrés oxidativo}

Algunos autores señalan que los macrófagos infiltrados en el tejido adiposo incrementan la producción de NADPH-oxidasa que genera especies reactivas de oxígeno. Cuando la producción de éstas es mayor que la capacidad de los antioxidantes enzimáticos (catalasa, superóxido dismutasa, glutatión peroxidasa, etcétera) o no enzimáticos (vitaminas $\mathrm{A}, \mathrm{C}$ y $\mathrm{E}$, minerales como el cinc y el cobre o carotenoides como el licopeno) se produce la oxidación de biomoléculas o estrés oxidativo, que promueve el daño de estructuras celulares, como el retículo endoplasmático, las mitocondrias y la membrana.
Así, de la peroxidación lipídica generada por el efecto de las especies reactivas de oxígeno en los lípidos de la membrana celular se originan isoprostanos inflamatorios, como las PGE, D, F y mayormente la 8 isoprostaglandina F2a, considerada marcador de daño oxidativo asociado con trastornos metabólicos.

El aumento de biomarcadores de estrés oxidativo en individuos obesos se adjudica a factores intrínsecos de la enfermedad; es decir, a su cualidad de enfermedad crónica inflamatoria y a cuestiones conductuales, como el bajo consumo de antioxidantes y el poco ejercicio. Además, las comorbilidades de la obesidad también se asocian con estrés oxidativo. ${ }^{56}$ Aunque el estrés oxidativo propio del asma parece no ser aditivo, éste podría favorecer una respuesta Th2 mediante la reducción de la producción de IL-12, además de disminuir la efectividad de los corticoesteroides.

\section{Estrés del retículo endoplasmático}

En la obesidad, la expansión del tejido adiposo y la consecutiva disminución de la irrigación sanguínea ocasionan, además de necrosis y apoptosis, daño o estrés del retículo endoplasmático en adipocitos; el daño en este organelo se observa también en hepatocitos, debido al aumento de ácidos grasos procedentes de la circulación y del tejido adiposo abdominal. ${ }^{57}$

Normalmente, en el retículo endoplasmático se forman y pliegan las proteínas. El estrés del retículo endoplasmático se determina por la producción de proteínas no plegadas (relacionadas con alteraciones en el calcio inducidas por diversos elementos como isquemia $y$ especies reactivas de oxígeno); al ser detectadas se produce una respuesta (UPR: unfolded protein response) para restablecer la función del retículo endoplasmático, que es manejada por tres moléculas: PERK (del inglés: protein ki- 
nase RNA-like endoplasmic reticulum kinase), IRE-1 (del inglés: inositol-requiring enzyme) y ATF-6 (del inglés: activating transcription factor). Estas moléculas actúan como sensores transmembranales de estrés del retículo endoplasmático y favorecen la restauración de las proteínas no plegadas. Si el estrés es muy severo o prolongado, la UPR no lo puede corregir y se estimulan vías de apoptosis, de inflamación o ambas.

En enfermedades crónicas como el asma resulta importante determinar si los factores genéticos pueden alterar el plegamiento de las proteínas en este organelo; al respecto se ha descrito la molécula producto del gen ORMDL3 (del inglés: orosomucoid like protein isoform) asociada con asma, alteraciones del calcio en el retículo endoplasmático y producción de proteínas no plegadas. ${ }^{58}$ ORMDL3 es un gen inducible por alergenos o citocinas como las IL-4 y 13, se expresa en el retículo endoplasmático del epitelio bronquial y se ha identificado como un gen de susceptibilidad al asma; en ratones se ha observado, además, que promueve el tráfico de eosinófilos, su activación y desgranulación por regulación de integrinas. ${ }^{59}$ ORMDL3 inhibe a la proteína SERCA (del inglés: sarcoendoplasmic reticulum calcium transport ATPase); la disminución de esta proteína favorece el estrés del retículo endoplasmático y la apoptosis celular; su expresión está disminuida en el músculo liso de las vías aéreas en el asma, lo que también puede deberse a las citocinas liberadas durante el proceso inflamatorio. ${ }^{60}$

\section{Disfunción mitocondrial}

Los elementos inductores de especies reactivas de oxígeno producen disfunción mitocondrial en el epitelio aéreo, lo que induce inflamación severa en individuos alérgicos. En el infiltrado inflamatorio, en el asma, aumenta la molécula 12/15-lox que induce la secreción de meta- bolitos del ácido linoleico (13-S-HODE), que por activación del TRPV (del inglés: transient receptor potential cation channel, subfamily$v)$ alteran la homeostasia del calcio, catión que al aumentar en la mitocondria induce su disfunción. Las mitocondrias disfuncionales producen especies reactivas de oxígeno y estrés oxidativo, que pueden estimular al inflamasoma. ${ }^{61}$

En la obesidad, una dieta elevada en grasas disminuye en el tejido adiposo la expresión y función del transportador TSPO (del inglés: translocator protein $18 \mathrm{kDa}) .{ }^{62}$ Esta molécula introduce colesterol a la mitocondria, en donde la proteína llamada StAR lo convierte en pregnenolona (precursor de las hormonas esteroideas). El transportador TSPO en la mitocondria regula la producción de ATP y especies reactivas de oxígeno e interviene en la apoptosis.

HSP60 (del inglés: heat shock protein) es una proteína mitocondrial esencial para la integridad de este organelo y la viabilidad celular. Regula el plegamiento de proteínas en la mitocondria y la apoptosis; cuando hay estrés celular aumenta su producción y puede ser exocitada o expresada en la superficie para establecer contacto con células del sistema inmunitario. En el hipotálamo de ratones obesos se ha observado que al disminuir la chaperona mitocondrial Hsp60 se produce disfunción mitocondrial y estrés oxidativo, lo que induce resistencia a la insulina y a la leptina; también se observó disminuida en cerebros de humanos diabéticos, ${ }^{63}$ obtenidos por autopsia.

\section{Migración y activación celular}

\section{Macrófagos}

La leptina producida en exceso en la obesidad y en el asma induce la expresión de moléculas de adhesión que actúan en colaboración 
con MCP-1(CCL-2) para inducir la migración de macrófagos. ${ }^{49}$ Otras moléculas implicadas en la migración de los macrófagos son la osteopontina, ${ }^{64}$ la IL-8 (CXCL8) y las citocinas proinflamatorias IL-1, IL-6 y TNF- $\alpha$ producidas por los adipocitos, además de las sustancias liberadas por la necrosis de estas células. ${ }^{49}$

La infiltración de los macrófagos es más intensa en el tejido blanco visceral que en el subcutáneo. Mientras que los macrófagos del tejido adiposo de individuos no obesos están activados de manera antiinflamatoria (M-2), los de pacientes obesos a su llegada y por acción de elementos como derivados de nutrientes, restos celulares y citocinas, cambian al fenotipo $\mathrm{M}-1$ que secreta moléculas inflamatorias, mismas que favorecen la resistencia a la insulina en los adipocitos..$^{49,65}$

\section{Linfocitos}

La expansión del tejido adiposo en obesidad se distingue, además, por la participación del sistema inmunitario adaptativo. Hay un cambio de fenotipo de los linfocitos $\mathrm{T}$ y reclutamiento de B y $\mathrm{T}$ (con predominio de CD8), favorecido por la quimiocina CCL-5, también conocida como RANTES (del inglés: regulated on activation normal $T$ cell expressed and secreted) ${ }_{1}^{66}$ que es liberada por células inflamatorias, como las cebadas.

Los TCD4, al ser activados por células locales, producen citocinas y quimiocinas, lo que favorece la infiltración de los macrófagos. Se ha señalado, incluso, que la acumulación de células T CD8+ precede a la infiltración de macrófagos en modelos de obesidad inducida por alimento. ${ }^{67}$

En la obesidad hay disminución en el tejido adiposo de linfocitos NKT, que a través de citocinas regulan la respuesta inmunitaria local. Disminuyen también los CD4 CD25-FoxP3, supresores de la respuesta inflamatoria y de la activación de los linfocitos. Lo señalado traduce la desregulación de la respuesta inmunitaria que ocurre en el tejido adiposo, que es considerado órgano central de la inflamación en obesidad; sin embargo, las secuelas resultantes son sistémicas. De manera similar, las células CD4CD25 FoxP3 circulantes están disminuidas en el individuo asmático. ${ }^{68}$

\section{Mastocitos y fibroblastos}

Los precursores hematopoyéticos del tejido adiposo pueden dar origen a mastocitos, ${ }^{69}$ mismos que, además de participar como células fagocíticas, tienen un papel esencial en la inflamación. Estas células progenitoras se han propuesto como las posibles causantes de las diferencias entre la hiperreactividad bronquial en modelos animales obesos y no obesos. ${ }^{69}$ En la obesidad aumenta el número de células cebadas que amplifican la inflamación y de fibroblastos, que además de secretar colágeno, liberan citocinas inflamatorias participantes en la producción de eosinófilos y otros granulocitos. ${ }^{70}$ Las células cebadas son inductoras esenciales de la inflamación en el asma; a su vez, los fibroblastos, en asma crónica, participan de manera importante en la fibrosis y la remodelación. ${ }^{70}$

\section{Remodelación}

En el asma, simultánea o consecutiva a la inflamación crónica, hay cambios estructurales que involucran a la composición y la organización de constituyentes celulares y moleculares de la pared bronquial. Estos cambios se distinguen en términos histopatológicos por: lesión epitelial, engrosamiento o fibrosis subepitelial, hipertrofia e hiperplasia de células caliciformes con hipersecreción mucosa, hiperplasia del músculo liso y remodelación vascular o angiogénesis.

Múltiples factores participan en la remodelación: fibroblastos, miofibroblastos, eosinófilos, 
histamina, triptasa, IL-13, factor transformante de crecimiento (TGF)- $\beta$, entre otros. Los cambios histopatológicos de la remodelación se asocian con hiperreactividad persistente de las vías aéreas, estrechamiento y finalmente, obstrucción. ${ }^{70}$

Poco se sabe acerca del efecto de la obesidad en la remodelación pulmonar por asma. Al respecto, un estudio realizado en ratones sanos y obesos retados con OVA mostró en los obesos un aumento en las fibras de colágeno de las vías aéreas y el parénquima pulmonar, actina de músculo liso en los bronquiolos terminales y conductos alveolares, así como de eosinófilos en lavado bronquial, al ser comparados con los no obesos. ${ }^{71}$

\section{Adipocinas}

El tejido adiposo secreta adipocinas con actividad proinflamatoria, como la leptina y la visfatina, o antiinflamatoria como la adiponectina, que funcionan como redes de señalización que comunican al tejido adiposo con diferentes órganos (cerebro, hígado, linfoides, etc.) y participan, además de la inflamación, en el metabolismo. ${ }^{72}$ Parecen ser importantes mediadores en la enfermedad de las vías aéreas en obesidad a través de efectos directos en ellas, más que por aumentar su inflamación.

\section{Leptina}

Entre otras células, es sintetizada por las del tejido adiposo, macrófagos, neuronas, linfocitos Th1 y expresan receptores para ella, las células epiteliales, pulmonares, macrófagos, linfocitos, neuronas, etcétera. Inhibe la producción de adiponectina, es proinflamatoria, aumenta en la obesidad y participa en el asma bronquial. Algunos estudios en niños muestran que aumenta en asmáticos no obesos, pero su incremento es mayor en los obesos. ${ }^{73}$

\section{Adiponectina}

Es sintetizada por el tejido adiposo visceral e inhiben su producción el TNF, la leptina, los corticoesteroides y la hipoxia. Tiene actividad antiinflamatoria y guarda una relación inversa con la masa del tejido adiposo y la edad. Disminuye en humanos obesos y en pacientes con resistencia a la insulina.

\section{Hiperreactividad de la vía aérea}

Una característica esencial del asma es la hiperreactividad de la vía aérea, que consiste en mayor sensibilidad de las células musculares lisas de la vía aérea ante un agonista constrictor. Se han realizado múltiples estudios en humanos para dilucidar si la obesidad aumenta la hiperreactividad de la vía aérea en niños y adultos, pero las pruebas no son concluyentes. No obstante, un estudio en pacientes obesos y asmáticos antes y 12 meses después de la cirugía bariátrica mostró mejoría significativa en la respuesta a la metacolina, disminución de IgE, aumento de los linfocitos en el lavado bronquial y de los linfocitos CD4+ periféricos. ${ }^{74}$

En los modelos animales obesos, la hiperreactividad de la vía aérea que se observa no requiere el estímulo constrictor, sino que se expresa de manera innata. Se piensa que el TNF- $\alpha$ liberado desde el tejido adiposo puede ser, al menos en parte, el responsable. La leptina también podría tener relación con la disminución del flujo aéreo; sin embargo, no puede adjudicarse a ésta el efecto constrictor total debido a que los modelos de ratones knock-out para el receptor de leptina $(\mathrm{db} /$ $d b$ ) también tienen hiperreactividad bronquial. ${ }^{75}$ Al ser administrada de manera continua, esta hormona incrementa la hiperreactividad de la vía aérea después del reto con ovalbúmina, pero no produce un patrón de citocinas de células Th2 ni aumenta la eosinofilia. ${ }^{75}$ 
Se ha explorado la posibilidad de que la activación de TLR esté detrás de la hiperreactividad de la vía aérea causada por la leptina, porque en los modelos animales de exposición al ozono, en los que está demostrado que estos receptores están implicados, ${ }^{76}$ hay aumento de citocinas inflamatorias. La vía aérea de los pacientes obesos muestra condiciones aumentadas de estrés oxidativo y, por tanto, los sensores de estrés del sistema inmunitario innato podrían ser activados.

$\mathrm{Al}$ respecto, las células asesinas naturales $\mathrm{T}$ (NKT) son capaces de detectar ciertos glicolípidos como desencadenantes de la hiperreactividad de la vía aérea, después de ser activadas por IL-33 proveniente de macrófagos. ${ }^{77}$ En los pacientes obesos, los lípidos oxidados podrían activar esas células. ${ }^{78}$ La hiperreactividad de la vía aérea en ratones obesos se asocia con células linfoides innatas ILC3 (del inglés: innate lymphoid cells) productoras de IL-17 en el pulmón. En lavados bronquiales de humanos con asma severa y obesidad también se obtuvieron células ILC3 y concentraciones aumentadas de IL-17. ${ }^{79}$

En lo referente a la participación de la adiponectina, antagonista de la leptina, en experimentos con ratones sensibilizados a ovoalbúmina se ha visto disminución de la hiperreactividad de la vía aérea, de los eosinófilos del lavado bronco-alveolar y de las citocinas Th2, cuando esta adipocina se administra mediante infiltración. A esta evidencia se suma el hallazgo de la hiperreactividad de la vía aérea aumentada en los ratones deficientes de adiponectina. ${ }^{80}$ Más aún, la respuesta a metacolina de los ratones, tras ser sensibilizados con ozono, es mayor en los que tienen deficiencia de adiponectina. ${ }^{81}$

La limitación del flujo aéreo, como sucede al contraerse el músculo liso bronquial, provoca que las demás zonas del pulmón se expandan, porque estas áreas reciben mayor proporción del volumen corriente. Esta expansión tensa al músculo liso y se suma a los problemas mecánicos de las vías aéreas que se comentan posteriormente.

\section{Disfunción respiratoria}

Las alteraciones respiratorias relacionadas con la obesidad van desde la simple alteración de la función ventilatoria, sin consecuencias en el intercambio gaseoso, hasta la insuficiencia respiratoria hipercápnica característica del síndrome de obesidad hipoventilación.

En individuos obesos, la masa corporal modifica el equilibrio de fuerzas entre la pared del tórax, la del abdomen y el pulmón, hay disminución en la amplitud y el movimiento de la pared torácica y el diafragma, lo que disminuye la expansión basal inspiratoria del pulmón y la capacidad residual funcional. Algunos autores han observado anormalidades en la resistencia y frecuencia en la oscilometría, a pesar del flujo normal detectado por espirometría, lo que sugiere una disfunción más distal..$^{82} \mathrm{El}$ aumento en el índice de masa corporal está asociado directamente con el grado de resistencia de las vías aéreas y el trabajo respiratorio. La reducción en la capacidad residual funcional y el volumen de reserva espiratoria están asociados con un estrechamiento temprano de las vías aéreas; esto causa alteraciones en la ventilación-perfusión y consecuentemente hipoxia, lo que se exacerba durante el sueño. ${ }^{83}$

\section{Síndrome de apnea-hipopnea del sueño obstructiva}

Corresponde a episodios recurrentes de colapso faríngeo parcial o completo durante el sueño. En el evento obstructivo de las vías aéreas hay cambios cíclicos en $\mathrm{O}_{2}$ y $\mathrm{CO}_{2}$ que generan hipoxemia e hipercapnia, con cambios de presión 
intratorácica negativa progresiva. La secuencia de desaturación y reoxigenación origina estrés oxidativo y la producción de especies reactivas de oxígeno, mismas que activan leucocitos, aumentan moléculas de adhesión, inducen disfunción endotelial, liberación de citocinas e inflamación sistémica. ${ }^{84,85}$ La apnea-hipopnea del sueño obstructiva está implicada en hipertensión sistémica y pulmonar, arritmias, infartos de miocardio y cerebrales.

Algunos mecanismos implicados en su origen son: a) el aumento de la grasa perilaríngea que incrementa la presión extraluminal sobre la vía aérea, b) las alteraciones anatómicas como la micrognatia y la hipertrofia del tejido amigdalino, c) la disminución del tono de los músculos laríngeos. Inicialmente los pacientes tienen ronquido, nicturia, boca seca al despertar, cefalea matutina y somnolencia.

El 40\% de los pacientes con apnea-hipopnea del sueño obstructiva tienen obesidad, proporción que puede llegar a $90 \%$ en personas con índice de masa corporal superior a 40. Esto puede explicarse por factores mecánicos, aunque hay informes que asocian a la leptina con la inflamación faríngea. Algunos estudios señalan que la apnea-hipopnea del sueño obstructiva puede contribuir significativamente al mal control del asma en pacientes obesos, así como a la inflamación sistémica que padecen.

\section{Síndrome de hipoventilación por obesidad}

El síndrome de hipoventilación por obesidad se manifiesta en ausencia de otras causas de hipoventilación (enfermedad pulmonar, debilidad neuromuscular, restricción esquelética, enfermedad pleural, hipotiroidismo) y se distingue por hiperpnea diurna, hipoventilación o apnea nocturna (o ambas), resistencia a la leptina, disfunción endotelial, inflamación sistémica. ${ }^{86}$ Las respiraciones son superficiales, lo que conduce a hipoxia crónica e hipercapnia, más acentuada por las mañanas, y cansancio con esfuerzos mínimos. Los obesos con hipoventilación crónica e hipercapnia con mayor frecuencia tienen hipertensión arterial, resistencia a la insulina, angina e insuficiencia cardiaca.

El $50 \%$ de los pacientes con obesidad severa (índice de masa corporal mayor de 50) tiene síndrome de hipoventilación por obesidad y la mayoría padece, además, apnea del sueño. ${ }^{87}$

\section{Reflujo gastroesofágico}

Las personas con sobrepeso $\mathrm{u}$ obesidad tienen mayor riesgo de padecer la enfermedad por reflujo gastroesofágico y sus complicaciones, como cáncer o esofagitis grave. Lo anterior ocurre debido a que en la obesidad hay retraso en el vaciamiento gástrico e incremento de la presión intraabdominal. Asimismo, aumentan los episodios de relajación del esfínter esofágico inferior.

El ácido que escapa en el esófago inferior estimula al nervio vago, que a su vez activa a las vías aéreas inferiores que provocan espasmo bronquial. Además, el ácido regurgitado al alcanzar la boca puede ser aspirado por las vías aéreas y ser el desencadenante del asma.

Debe sospecharse en pacientes asmáticos cuando hay poca respuesta a medicamentos, el episodio de asma es precedido por pirosis o regurgitación, los ataques empeoran con el ejercicio o después de comer. ${ }^{88}$

\section{CONCLUSIÓN}

Algunas de las asociaciones señaladas entre asma y obesidad varían no sólo entre el humano y el ratón, sino en los grupos de la misma especie con diferencias en edad y métodos de estudio. Sin embargo, la coincidencia de varios inductores y 
elementos que exacerban ambos padecimientos, así como en vías moleculares compartidas, pone de manifiesto la relación existente entre ambas enfermedades. Asimismo, permite inferir que la obesidad puede incidir en el asma por diversos mecanismos, entre los que destacan los de origen mecánico, hormonal o inflamatorio.

\section{REFERENCIAS}

1. Olaiz-Fernández G, Rivera Dommarco J, Shamah-Levy T, et al. Encuesta Nacional de Salud y Nutrición. Cuernavaca, México: Instituto Nacional de Salud Pública, 2006.

2. Ford ES. The epidemiology of obesity and asthma. J Allergy Clin Immunol 2005;115:897-909.

3. Farah CS, Kermode JA, Downie SR, et al. Obesity is a determinant of asthma control, independent of inflammation and lung mechanics. Chest 2011;140:659-666.

4. Tantisira KG, Weiss S. Complex interaction in complex traits: obesity and asthma. Thorax 2001;56:64-74.

5. Barquera S, Campos-Nonato I, Hernández-Barrera L, et al. Prevalencia de obesidad en adultos mexicanos, ENSANUT 2012. Salud Pública 2013;55:151-160.

6. García-Sancho C, Fernández-Plata R, Martínez-Briseño D, et al. Adult asthma in Mexico City: A population-based study. Salud Pública Mex 2012;54:425-432.

7. Almeida VP, Guimaraes FS, Mogo VJ, et al. Correlation between pulmonary function, posture and body composition in patients with asthma. Rev Port Pneum 2013;19:204-210.

8. Farah CS, Salome CM. Asthma and obesity: a known association but unknown mechanism. Respirology 2012;17:412-421.

9. Szczepankiewicz A, Breborowicz A, Sobkowiak P, et al. Are genes associated with energy metabolism important in asthma and BMI? J Asthma 2009;46:53-58.

10. Saadi A, Gao G, Li H, et al. Association study between vitamin $D$ receptor gene polymorphisms and asthma in the Chinese Han population: a case-control study. BMC Med Genet 2009;10:71-77.

11. Takiishi T, Gysemans C, Bouillon R, et al. Vitamin D and diabetes. Endocrinol Metab Clin North Am 2010;39:419-446.

12. Melen E, Himes BE, Brehm JM, et al. Analyses of shared genetic factors between asthma and obesity in children. $J$ Allergy Clin Immunol 2010;126:631-637.

13. Tesse R, Schieck M, Kabesch M. Asthma and disorders: shared mechanisms and genetic pleiotropy. Mol Cell Endocrinol 2011;333:103-111.

14. Litonjua AA, Gold DR. Asthma and obesity: common earlylife influences in the inception of disease. J Allergy Clin Immunol 2008;121:1075-1084.
15. Patel SP, Rodriguez A, Little MP, et al. Associations between pre-pregnancy obesity and asthma symptoms in adolescents. J Epidemiol Community Health 2012;66:809-814.

16. Ramírez-Velez R. In utero fetal programming and its impact of health in adulthood. Endocrinol Nutr 2012;59:383-393.

17. Korn $S$, Hübner $M$, Jung $M$, et al. Severe and uncontrolled adult asthma is associated with vitamine $D$ insufficiency and deficiency. Resp Res 2013;14:25-30.

18. Litonjua AA. Childhood asthma may be a consequence of vitamin D deficiency. Curr Opin Allergy Clin Immunol 2009;9:202-207.

19. Feng L, Li JR, Yang F. Relationship of serum 25-hydroxyvitamin $D$ with obesity and inflammatory cytokines in children. Zhongguo Dang Dai Er Ke Za Zhi 2013;15:875-879.

20. Allan K, Kelly FJ, Devereux G. Antioxidants and allergic disease: a case of too little or too much? Clin Exp Allergy 2010;40:370-380.

21. Dasarathy J, Periyalwar P, Allampati S, et al. Hypovitaminosis $D$ is associated with increased whole body fat mass and greater severity of non-alcoholic fatty liver disease. Liver Int 2014;34:118-127.

22. Wassall H, Devereaux G, Seaton A, et al. Complex effects of vitamin $\mathrm{E}$ and vitamin $\mathrm{C}$ supplementation on in vitro neonatal mononuclear cell responses to allergens. Nutrients 2013;5:3337-3351.

23. Wu G, Chen J, Hoffman C, et al. Linking long-term dietary patterns with gut microbiol enterotypes. Science 2011;334:105-108.

24. Shen J, Obin MS, Zhao L. The gut microbiota, obesity and insulin resistance. Mol Aspects Med 2013;34:39-58.

25. Strober W. Impact of the gut microbiome on mucosal inflammation. Trends Immunol 2013;34:423-430.

26. Cani PD, Neyninck AM, Fava F, et al. Selective increases of bifidobacteria in gut microflora improve high-fat-dietinduced diabetes in mice through a mechanism associated with endotoxaemia. Diabetología 2007;150:2374-2383.

27. Karlsson C, Onnerfalt J, Xu J, et al. The microbiota of the gut in preschool children with normal and excessive body weight. Obesity 2012;20:2257-2261.

28. Palacios $\mathrm{T}$, Coulson $\mathrm{S}$, Butt $\mathrm{H}$, et al. The gastrointestinal microbiota and multi-strain probiotic therapy: in children and adolescent obesity. Adv Integrative Med 2014;1:2-8.

29. Ly NP, Litonjua A, Gold DR, et al. Gut microbiota, probiotics, and vitamin $\mathrm{D}$ : Interrelated exposures influencing allergy, asthma, and obesity? J Allergy Clin Immunol 2011;127:1087-1094.

30. Chen $Y$, Dales $R$, Tang $M$, et al. Obesity may increase the incidence of asthma in women but not in men: longitudinal observation from the Canadian National Population Health Surveys. Am J Epidemiol 2002;155:191-197.

31. Vega-Robledo GB, Valencia-Zavala P, Sánchez-Olivas M, et al. Asociación de obesidad y asma alérgica en adultos. Rev Alerg Méx 2012;59:173-179. 
32. Hamano N, Terada N, Maesako K, et al. Effect of female hormones on the production of IL-4 and IL-13 from peripheral blood mononuclear cells. Acta Otolaringol 1998;537:27-31.

33. Varraso R, Siroux V, Maccario J, et al. Epidemiological study on the genetics and environment of asthma. Asthma severity is associated with body mass index and early menarche in women. Am J Respir Crit Care Med 2005;171:334-339.

34. Sood A, Qualls C, Li R, et al. Lean mass predicts asthma better than fat mass among females. European Resp J 2011;37:65-71.

35. Wang FV, Soronen J, Turpeinen U, et al. 17ß-estradiol and estradiol fatty acyl esters and estrogen-converting enzyme expression in adipose tissue in obese men and women. J Clin Endocrinol Metab 2013;98:4923-4931.

36. Davis KE, Neinast MD, Sun K, et al. The sexually dimorphic role of adipose and adipocyte estrogen receptors in modulating adipose tissue expansion, inflammation and fibrosis. Mol Metab 2013;2:227-242.

37. D'Eon TM, Souza SC, Aronovitz M, et al. Estrogen regulation of adiposity and fuel partitioning. Evidence of genomic and non-genomic regulation of lipogenic and oxidative pathways. J Biol Chem 2005;280:35983-35991.

38. Holguin F, Rojas M, Brown LA, et al. Airway and plasma leptin and adiponectin in lean and obese asthmatics and controls. J Asthma 2011;48:217-223.

39. Sutherland ER, Goleva E, Strand M, et al. Body mass and glucocorticoid response in asthma. Am J Respir Crit Care Med 2008;178:682-687.

40. Giouleka P, Papatheodorou G, Lyberopoulos P, et al. Body mass index is associated with leukotriene inflammation in asthmatics. Eur J Clin Invest 2011;41:30-38.

41. Goleva E, Hauk PJ, Hall CF, et al. Corticosteroid-resistant asthma is associated with classical antimicrobial activation of airway macrophages. J Allergy Clin Imm 2008;122:550-559.

42. Barnes PJ, Adcock IM, Ito K. Histone acetylation and deacetylation: importance in inflammatory lung diseases. Eur Respir J 2005;25:552-563.

43. Kim SH, Sutherland ER, Gelfand EW. Is there a link between obesity and asthma? Allergy Asthma Immunol Res 2014;6:189-195.

44. Holgate ST. The airway epithelium is central to the pathogenesis of asthma. Allergol Int 2008;57:1-10.

45. Tilg $\mathrm{H}$, Moschen RA. Role of adiponectin and PBEF/ visfatin as regulators of inflammation: involvement in obesity-associated diseases. Clinical Science 2008;114:275-288.

46. Fontana L, Eagon JC, Trujillo ME, et al. Visceral fat adipokine secretion is associated with systemic inflammation in obese humans. Diabetes 2007;36:1010-1013.

47. Wellen E, Fucho R, Gregor MF, et al. Coordinated regulation of nutrient and inflammatory responses by STAMP- 2 is essential for metabolic homeostasis. Cell 2007;129:537-548.

48. Davis JE, Braucher DR, Walker-Daniels J, et al. Absence of TIr2 protects against high-fat diet-induced inflammation and results in greater insulin-stimulated glucose transport in cultured adipocytes. J Nutr Biochem 2011;22:136-141.

49. De Luca C, Olefsky J. Inflammation and insulin resistance. FEBS Lett 2008;582:97-105.

50. Stientstra R, Tack $C$, Kanneganti $T$, et al. The inflammasome puts obesity in the danger zone. Cell Metabolism 2012;15:10-12.

51. Besnard AG, Guillou N, Tschopp J, et al. NLRP3 inflammasome is required in murine asthma in the absence of aluminum adjuvant. Allergy 2011;66:1047-1057.

52. Medina-Gómez $\mathrm{G}$. Mitochondria and endocrine function of adipose tissue. Best Practice Res Clin Endocrinol Metabol 2012;26:791-804.

53. Trayhurn P, Wang B, Wood IS. Hypoxia in adipose tissue: a basis for the dysregulation of tissue function in obesity? Br J Nutr 2008;100:227-235

54. Wood IS, de Heredia FP, Wang B, et al. Cellular hypoxia and adipose tissue dysfunction in obesity. Proc Nutr Soc 2009;68:370-377

55. Eltzschig HK, Carmeliet P. Hypoxia and inflammation. $\mathrm{N}$ Engl J Med 2011;364:656-665.

56. Holguin F, Fitzpatrick A. Obesity, asthma, and oxidative stress. J Appl Physiol 2010;108:754-759.

57. Hotamisligil GS. Endoplasmic reticulum stress and the inflammatory basis of metabolic disease. Cell 2010;140:900917.

58. Cantero G, Fandos C, Valverde A, et al. The asthma associated ORMDL3 gene product regulates endoplasmic reticulum mediated calcium signaling and cellular stress. Hum Mol Genet 2010;19:111-121.

59. Rao S, Gil H, Na Ge X, et al. ORMDL3 promotes eosinophil trafficking an activation via regulation of integrins and $C D$ 48. Nat Commun 2013;4:452-479.

60. Mekahli D, Bultynck G, Parys J, et al. Endoplasmic-reticulum calcium depletion and disease. Cold Sring Harb Perspect Biol 2011;3:a004317.

61. Mabalirajan U, Ghosh B. Mitochondrial dysfunction in metabolic syndrome and asthma. J Allergy (Cairo) 2013:340476. Doi: 10.1155/2013/340476.

62. Jaremko L, Jaremko M, Giller K, et al. Structure or the mitochondrial translocator protein in complex with a diagnostic ligand. Science 2014;343:1363-1366.

63. Kleinridders $\mathrm{A}$, Lauritzen $\mathrm{H}$, Ussar $\mathrm{S}$, et al. Leptin regulation of Hsp 60 impacts hypothalamic insulin signaling. J Clin Invest 2013;123:4667-4680.

64. Nomiyama T, Perez-Tilve D, Ogawa D, et al. Osteopontin mediates obesity-induced adipose tissue macrophage infiltration and insulin resistance in mice. J Clin Invest 2007;117:2877-2888.

65. Lumeng CN, Bodzin JL, Saltiel AR. Obesity induces a phenotypic switch in adipose tissue macrophage polarization. J Clin Invest 2007;117:175-184. 
66. Wu H, Ghosh S, Perrad XD, et al. T cell accumulation and regulated on activation, normal $T$ cell expressed and secreted upregulation in adipose tissue in obesity. Circulation 2007;115:1029-1038.

67. Nishimura S, Manabe I, Nagasaki M, et al. CD8+ effector T cells contribute to macrophage recruitment and adipose tissue inflammation in obesity. Nat Med 2009;15:914-920.

68. Provoost S, Anaes T, VanDurme Y, et al. Decreased FoxP3 protein expression in patients with asthma. Allergy 2009;64:1539-1546.

69. Poglio S, De Toni-Costes F, Arnaud E, et al. Adipose tissue as a dedicated reservoir of functional mast cell progenitors. Stem Cells 2010;28:2065-2072.

70. Pare PD, McParland E, Seow CY. Structural basis for exaggerated airway narrowing. Can J Physiol Pharmacol 2007;85:653-658.

71. Saraiva SA, Silva AL, Xisto DG, et al. Impact of obesity on airway and lung parenchyma remodeling in experimental chronic allergic asthma. Resp Physiol Neurobiol 2011;177:141-148.

72. Fuentes E, Fuentes F, Vilahuer G, et al. Mechanisms of chronic state of inflammation as mediators that link obese adipose tissue and metabolic syndrome. Mediat Inflamm 2013; doi. Org/10.1155/2013/136584.

73. Youssef D, Elbhedy R, Shakry D, et al. P48- Leptin, IL-4, IFN in obese asthmatic children. Clin Transl Allergy 2014;4:103. Doi: 10.1186/2045-7022-4-S1-103.

74. Dixon AE, Pratley RE, Forgione PM, et al. Effects of obesity and bariatric surgery on airway hyperresponsiveness, asthma control, and inflammation. J Allergy Clin Immunol 2011;128:508-515.

75. Shore SA, Schwartzman IN, Mellema MS, et al. Effect of leptin on allergic airway responses in mice. J Allergy Clin Immunol 2005;115:103-109.

76. Williams AS, Leung SY, Nath $P$, et al. Role of TLR2, TLR4, and MyD88 in murine ozone-induced airway hyperresponsiveness and neutrophilia. J Appl Physiol 2007;103:1189-1195.

77. Kim HY, Chang YJ, Subramanian S, et al. Innate lymphoid cells responding to IL-33 mediate airway hyperreactivity independently of adaptive immunity. J Allergy Clin Immunol 2012;129:216-227.

78. Gwang Cheon J. Natural killer T cell and pathophysiology of asthma. Korean J Pediatr 2010;53:136-145.

79. Kim HY, Lee HJ, Chang YJ, et al. IL-17 producing innate lymphoid cells and the NLRP-3 inflammasoma facilitate obesity-associated airway hyperrreactivity. Nat Med 2013 doi:10.1038/nm3423.

80. Shore SA, Terry SD, Flynt L, et al. Adiponectin attenuates allergen-induced airway inflammation and hyperresponsiveness in mice. J Allergy Clin Immunol 2006;118:389-395.

81. Zhu M, Hug C, Kasahara DI, et al. Impact of adiponectin deficiency on pulmonary responses to acute ozone exposure in mice. Am J Respir Cell Mol Biol 2010;43:487-497.

82. Openheimer B, Berger K, Segal L, et al. Airway dysfunction in obesity: response to voluntary restoration of end expiratory lung volume. PLOS one 2014;doi: 10.1371/journal. pone.0088015. PLoS One 2014;9:88015.

83. Krishnarpan Ch, Chetana S. Respiratory morbidity in obesity, beyond obstructive sleep apnea. Ann Thorac Med 2014;9:182-183.

84. Foster G, Poulin M, Hanly P. Intermittent hypoxia and vascular function: implications for obstructive sleep apnea. Exp Physiol 2007; 92:51-65.

85. Levy $\mathrm{P}$, Tannisler $\mathrm{C}$, Launois $\mathrm{S}$, et al. Sleep apnea syndrome in 2011: current concepts and future directions. Eur Resp Rev 2011;20:134-146.

86. Piper AJ, Grunstein R. Obesity hypoventilation syndrome: mechanisms and management. Am J Resp Crit Care Med 2011;183:292-298.

87. Karnatovskaia LV, Lee AS, Bender SP, et al. Obstructive sleep apnea, obesity, and the development of acute respiratory distress syndrome. J Clin Sleep Med 2014;10:657-662.

88. Dixon AE, Clerisme-Beaty EM, Sugar EA, et al. Effects of obstructive sleep apnea and gastroesophageal reflux disease on asthma control in obesity. J. Asthma 2011;48:707-713. 